\title{
A IMPORTÂNCIA DA EDUCAÇÃO FINANCEIRA NA UNIVERSIDADE: UM ENFOQUE PARA A FORMAÇÃO PROFISSIONAL E PESSOAL DE ESTUDANTES UNIVERSITÁRIOS
}

\author{
Valdemir José Máximo Omena da SILVA ${ }^{1}$ \\ Silvana Neumann MARTINS ${ }^{2}$ \\ Samuel Martim de CONTO ${ }^{3}$ \\ Eloni José SALVI ${ }^{4}$
}

\begin{abstract}
Resumo
O presente artigo tem como objetivo analisar a importância da Educação Financeira para os alunos universitários de uma Instituição de Ensino Superior (IES) localizada no Rio Grande do Sul. A fundamentação teórica é baseada em: Savoia (2007); Pereira (2009); Ewald (2011); Monteiro (2012); Bacen (2013); Hofman e Moro (2013) e Modernell (2014). Neste estudo, que possui uma abordagem qualitativa, os dados coletados foram adquiridos mediante a aplicação de questionário contendo cinco questões. Os alunos envolvidos são graduandos de uma Instituição de Ensino Superior localizada do Rio Grande do Sul. Esses estudantes são ligados ao Centro de Gestão Organizacional - CGO por meio da disciplina Finanças Pessoais. Os dados coletados permitiram construir três categorias de análise iniciais: a) a aquisição e difusão do conhecimento apreendido; b) a disciplina sobre Educação Financeira; e c) a integração entre professor e aluno no processo de ensino e de aprendizagem. Para análise dos dados, utilizou-se a técnica da análise de conteúdo. Os resultados apontam a importância da Educação Financeira na formação pessoal e profissional da pessoa. Apontaram também que seja disponibilizada o quanto antes na formação básica nas escolas para que o ser humano, em idade adulta, consiga planejar seus gastos com responsabilidade e equilíbrio.
\end{abstract}

Palavras-chave: Comunidade. Educação Financeira. Ensino Médio. Finanças Pessoais. Universitários.

\section{INTRODUÇÃO}

A Educação Financeira tem motivado os pesquisadores sobre vários aspectos, porque sua aplicação pode contribuir na formação de jovens, tornando-os adultos que compreendam melhor o gerenciamento de suas finanças pessoais. Os saberes acerca desse tema fazem com que o indivíduo saiba administrar os recursos financeiros pessoais em equilíbrio com o mercado econômico vigente (SAVOIA 2007). Desse modo, quando incluída nos currículos das escolas e nas atividades educacionais, desde o início de sua formação, os alunos podem lidar melhor com seus recursos financeiros, acarretando uma melhor qualidade de vida na fase adulta. Foi

\footnotetext{
${ }^{1}$ Universidade do Vale do Taquari (Univates), Lajeado - RS - Brasil. Doutorando do Programa de Pós-graduação em Ensino pela Univates em PPGEnsino - Univates. Bolsista (FAPERGS - CAPES). E-mail: valdemir.silva@universo.univates.br.

${ }^{2}$ Universidade do Vale do Taquari (Univates), Lajeado - RS - Brasil. Mestrado e Doutorado em Educação pela PUCRS. Docente permanente do Mestrado Profissional em Ensino de Ciências Exatas e do Mestrado Acadêmico em Ensino da Univates. E-mail: smartins@ universo.univates.br. (Orientadora)

${ }^{3}$ Universidade do Vale do Taquari (Univates), Lajeado - RS - Brasil. Mestre em Administração pela UFRGS, Doutor em Administração pela UNISINOS. Docente do Vale do Taquari. E-mail: samuelc@ universo.univates.br

${ }^{4}$ Universidade do Vale do Taquari (Univates), Lajeado - RS - Brasil. Mestre em Administração. Docente da Universidade do Vale do Taquari. Coordenador da Pós-Graduação Lato Sensu do CGO. Coordenador do CRIE Núcleo de Criatividade, Inovação e Empreendedorismo. E-mail: esalvi@universo.univates.br
} 
pensando nisso que foi criada, pelo Decreto Federal 7.397/2010, a Estratégia Nacional de Educação Financeira (ENEF, 2011), cujo objetivo é incentivar ações de Educação Financeira que ajudem as pessoas a tomarem decisões financeiras de uma maneira mais consciente. Já em nível mundial, a Organização para Cooperação e Desenvolvimento Econômico - OECD (Organization for Economic Co-operation and Development) define a Educação Financeira como uma associação de conhecimento, atitude, habilidades e comportamento consciente intrínseco à tomada de decisões financeiras, buscando alcançar o ponto de equilíbrio pessoal (OECD, 2012).

Diante disso, foi desenvolvido, na universidade foco deste estudo, um projeto de extensão cujo lócus das atividades foram as escolas de Ensino Médio do Vale do Taquari. O conjunto de atividades propostas nesse projeto desenvolve habilidades e competências, como também, o espírito crítico e criativo dos alunos, contribuindo no delineamento da formação pessoal e profissional dos envolvidos. Assim, transpondo os limites internos da sala de aula, o projeto visa disseminar para as comunidades regionais do Vale do Taquari a cultura da educação de equilíbrio nas finanças.

Diante disso, esta publicação busca analisar a importância da Educação Financeira para os alunos universitários de uma Instituição de Ensino Superior (IES) localizada no Rio Grande do Sul.

\section{REFERENCIAL TEÓRICO}

\subsection{Educação Financeira}

Refletir sobre os problemas financeiros não é prática desse século. Desde os tempos da Idade Média, mesmo não usado o conceito de Educação Financeira, já se expressava uma preocupação sobre as finanças em vários contextos. Pensar sobre o assunto sem ao menos definir um espaço para que esse conhecimento seja adquirido torna-se tarefa utópica quando se deseja desenvolver suas práticas.

É muito comum ver em pesquisas científicas e em dados publicados pelos órgãos especializados que a população em geral não dispõe de conhecimentos básicos sobre como equilibrar suas finanças. Esse desequilíbrio é o principal ponto negativo para o atual problema. Fato esse é confirmado pelo Bacen (2013):

A ausência de educação financeira, aliada à facilidade de acesso ao crédito, tem levado muitas pessoas ao endividamento excessivo, privando-as de parte de sua renda em função do pagamento de prestações mensais que reduzem suas capacidades de consumir produtos que lhes trariam satisfação (BACEN, 2013 p.1). 
A contribuição para o entendimento sobre a Educação Financeira vem de Teixeira (2010) ao dizer que "a arte de aplicar os princípios e conceitos de finanças em auxilio à tomada de decisões financeiras pessoais" (TEIXEIRA 2010, p. 27). Essa ideia recebe um complemento do Banco Central do Brasil - BACEN, quando afirma que a Educação Financeira é:

[...] o processo mediante o qual os indivíduos e as sociedades melhoram sua compreensão dos conceitos e produtos financeiros. Com informação, formação e orientação claras, as pessoas adquirem os valores e as competências necessários para se tornarem conscientes das oportunidades e dos riscos a elas associados e, então, façam escolhas bem embasadas, saibam onde procurar ajuda e adotem outras ações que melhorem o seu bem-estar. Assim, a Educação Financeira é um processo que contribui, de modo consistente, para a formação de indivíduos e sociedades responsáveis, comprometidos com o futuro (BACEN, 2013, p. 1).

Pensando nesta perspectiva, os atores Hofman e Moro (2013) destacam o fato de que:

Atualmente, as crianças participam ativamente da economia como consumidores, e por isso, é indispensável, que as devidas orientações sobre a Educação Financeira sejam repassadas a elas desde logo cedo integrado à Matemática Financeira no currículo escolar (HOFMAN \& MORO, 2013 p.53).

Inserida na base curricular da escola, a Educação Financeira pode estimular os alunos a consumirem de maneira responsável. Além disso, pode criar oportunidades de conhecerem e manusearem corretamente o dinheiro, proporcionando mais equilíbrio e melhor qualidade financeira na fase adulta. Os autores Hofman e Moro (2013) ainda destacam que:

Muitas das competências e dos conhecimentos matemático financeiro necessários para promover a educação financeira passam a ter, como principal meio de disseminação, a escola. A relação entre educação financeira e escola torna-se indissociável, não cabendo isolá-la como disciplina autônoma, hermética e estanque: o mais apropriado seria tomá-la transversalmente (HOFMAN \& MORO, 2013 p.49).

Assim, a escola assume importante função na formação dos alunos, não somente pelo conteúdo teórico de sala de aula, mas pela formação cidadã consciente e crítica. Daí a importância da Educação Financeira na formação inicial do aluno. No ambiente escolar, o desenvolvimento de projetos voltados para a Educação Financeira precisa proporcionar o acesso a esse conhecimento através de disciplinas que acompanhe o aluno desde o ensino fundamental até o superior. Dessa forma, o aluno terá subsídios para inserir essa cultura conjuntamente à família (EWALD, 2011; FRANZONI et al, 2018).

A importância da Educação Financeira segundo Kioyosaki e Lechter (2000) está em:

[...] formar profissionais conscientes e capacitados para o mundo moderno, porque os alunos deixam a escola sem ter despertado para as questões financeiras. Ainda o autor 
afirma que o que falta em sua Educação não é saber ganhar dinheiro, mas como aplicálo mediante as escolhas feitas (KIOYOSAKI \& LECHTER, 2000, p.81).

Nesse contexto, a Educação Financeira surge estrategicamente nas escolas para orientar, desde as bases educacionais, os alunos nas melhores práticas de manusear as finanças e tomar as melhores decisões. Os resultados, provavelmente, serão vistos de forma positiva à medida que são oportunizadas de geração a geração, bem como uma abordagem a cada faixa etária, visando um melhor aproveitamento.

\subsection{Educação Financeira na Escola}

Os conhecimentos adquiridos na escola - aprender a ler, a escrever, a se comunicar em sociedade - servem como base para desenvolver suas habilidades pessoais e profissionais na vida adulta. Contudo, a inclusão da disciplina de Educação Financeira no currículo escolar pode contribuir para o entendimento da realidade em que o contexto econômico do país está passando. Boa parte dos alunos não tem a oportunidade de aprender sobre Educação Financeira e acabam saindo da escola com déficit em saber controlar o seu próprio dinheiro. Foi o que contribuiu Martins (2004) ao dizer:

Uma criança passa oito anos no ensino fundamental, três anos no ensino médio e, durante esses onze anos de educação básica, é obrigada a memorizar nomes e datas de pouca utilidade na vida real. Nesses onze anos, o aluno não estuda noções de comércio, economia, finanças ou impostos. O sistema educacional ignora o assunto “dinheiro", algo incompreensível, já que a alfabetização financeira é fundamental para ser bem-sucedido em um mundo complexo. [...] não tenho dúvida que essa falha é responsável por muitos fracassos pessoais e familiares (MARTINS, 2004 p.5).

Com a globalização, observa-se que o desenvolvimento econômico faz criar demandas no mercado geral. O entrave na resolução de problemas oriundos dos recursos financeiros tem exigido o aprofundamento sobre esse assunto quanto à inserção da Educação Financeira na matriz curricular das escolas (FAVERI, KROETZ \& VALENTIM, 2013). A discussão sobre a importância da Educação Financeira na escola ganhou reforço através do programa do governo, "Estratégia Nacional de Educação Financeira - (ENEF, 2011), cujo objetivo é incluir a disciplina de Finanças nas matrizes curriculares das escolas públicas e privadas de âmbito Federal, Estadual e Municipal. Isso pode contribuir na capacidade do aluno de controlar suas finanças, corroborando com a educação contemporânea, em que a autonomia fortalece o aluno não somente para as questões pessoais, como, também, coletivamente (MONTEIRO, 2012). A aplicação da Educação Financeira em sala de aula, “deve ser visto como um conjunto de hábitos financeiros saudáveis" (MODERNELL, 2014 p.7). Ainda destaca o autor que: 
A Educação Financeira não é modismo. Chegou para fazer parte da vida e da formação das pessoas, da rotina e do programa das escolas, tão importante quanto a educação alimentar e a educação ambiental, pois são fundamentos que precisam acompanhar as pessoas por toda a vida e farão a diferença na forma de viver e no legado que deixarão (MODERNELL, 2014 p.6).

A inclusão da disciplina de Finanças na matriz curricular contribuirá para que o aluno atinja a idade adulta com mais responsabilidade, sabendo planejar melhor seus gastos. Cabe aqui evidenciar que ter uma vida financeira equilibrada não apresenta relação direta ao quanto a pessoa ganha, porque quem não consegue administrar com pouco, fatalmente terá dificuldades com maiores somas (PEREIRA et al, 2009).

Assim, conhecer mais sobre a Educação Financeira já desde o início da vida escolar, mesmo que de forma básica, é essencial para que o aluno, na fase adulta, tenha o mínimo de conhecimento necessário para administrar seus recursos financeiros.

\section{METODOLOGIA}

Este projeto abrangeu a região do Vale do Taquari, cujo objetivo foi desenvolver ações vinculadas à Educação Financeira pessoal, com ênfase na construção e no resgate de processos de ensino norteados por metodologias ativas, que visam desenvolver o espírito crítico e criativo dos alunos do Ensino Médio de todas escolas da região. Além disso, o projeto revestiu-se de grande importância por aproximar a teoria da Educação Financeira aos jovens, estimulando-os para o desenvolvimento de sua capacidade intrínseca, na busca de oportunidades de melhor gerenciamento dos seus recursos patrimoniais quando adultos, a fim de minimizar os efeitos sociais negativos que sua má gestão provoca. $\mathrm{O}$ desconhecimento de tais princípios desde o início da formação educacional cria hábitos inadequados, os quais dificilmente são alterados na vida adulta. O projeto propiciou aos envolvidos a realização de práticas que envolvem o planejamento e controle das finanças pessoais, aspectos que podem e devem ser estendidos às relações familiares.

As ações desse projeto de extensão foram realizadas em parceria com a disciplina Finanças Pessoais, ofertada pelo Centro de Gestão Organizacional de uma universidade localizada na região do Vale do Taquari/RS, com objetivo de analisar a importância da Educação Financeira para os graduandos de uma Instituição de Ensino Superior (IES) localizada no Rio Grande do Sul. No total, foram 25 graduandos voluntários, acompanhados pelos professores do projeto, que desenvolveram as atividades nas escolas do Ensino Médio do Vale do Taquari. 
A vinculação do projeto de extensão com a disciplina Educação Financeira dá um caráter interdisciplinar à proposta, visto que envolve temas dos seguintes cursos do Centro de Gestão Organizacional: a) Administração e suas linhas de formação específica; b) Ciências Contábeis, Gestão de Micro e Pequenas Empresas; c) Gestão de Recursos Humanos; d) Gestão Financeira e Logística.

Inicialmente, o professor da disciplina de Educação Financeira apresentou para os estudantes os temas e os conteúdos específicos a serem abordados nas oficinas com os alunos do Ensino Médio. Após isso, os graduandos, organizados em equipes, prepararam todos os materiais (apostilas, textos, planilhas, vídeos, exercícios, slides e outros materiais didáticos). Além de preparar os materiais, os graduandos simularam algumas oficinas em sala de aula, orientados pelo professor, com intuito de dirimir algumas dúvidas finais. Finalizadas as simulações, os graduandos agendaram a realização das oficinas com as escolas de Ensino Médio localizadas no Vale do Taquari. Para cada equipe de graduando, foi definido um professor orientador para acompanhar os estudantes na realização da oficina na escola. Esse orientador foi escolhido dentre os professores universitários integrantes do projeto. Cada oficina teve duração de quatro horas cada. Algumas foram desenvolvidas em apenas uma etapa de quatro horas, e outras foram desenvolvidas em dois momentos, de duas horas cada. As realizadas em duas etapas ocorreram com intervalo mínimo de 15 dias entre a primeira e a segunda.

Ao final do projeto, realizado nessa disciplina, contou-se com 14 equipes de graduandos, distribuídos em 12 escolas de Ensino Médio. Dessa forma, foi possível que aproximadamente 600 alunos do Ensino Médio participassem das oficinas oferecidas.

Nas oficinas foram abordados assuntos como receitas, despesas, investimentos, planejamento financeiro pessoal, controle de despesas pessoais, orçamento e fluxo de caixa pessoal, juros, armadilhas que corroem o orçamento familiar e dicas para enxugar/cortar gastos. Os materiais utilizados foram entregues aos alunos das escolas do Ensino Médio do Vale do Taquari pelos graduandos voluntários, quando da realização das atividades.

Quanto aos métodos utilizados, esta pesquisa classifica-se em: bibliográfica, qualitativa e descritiva. A pesquisa bibliográfica "é desenvolvida com base em material já elaborado, constituído principalmente de livros e artigos científicos" (GIL 2002, p.45). O autor aponta que a principal vantagem dessa pesquisa consiste em permitir maior abrangência de fenômenos, do que aquela realizada diretamente. Para que se alcançasse uma melhor relação entre a teoria e a prática, no método qualitativo, o pesquisador é convidado a aprofundar sua compreensão sobre os conceitos estudados, em que possa interpretá-los segundo os pontos de vista do seu objeto de pesquisa (ALVES, 1991). Ainda conforme o autor, o método qualitativo permite coletar as 
perspectivas dos participantes percebendo a diferença entre as respostas e seus comportamentos ao longo do desenvolvimento do projeto. A pesquisa descritiva, por sua vez, descreve com mais detalhes um fenômeno real, cujas informações realçam a respeito do que se pretende investigar (TRIVIÑOS, 2008).

No início e ao final das oficinas, foi aplicado um instrumento de coleta de dados com 25 graduandos (identificados nesse estudo como A1, A2 e assim sucessivamente, até A25), no qual constaram questões que avaliaram os conteúdos trabalhados e as atividades desenvolvidas durante a oficina, constituindo numa base de dados que são utilizadas na escrita dessa produção científica. $\mathrm{O}$ instrumento de pesquisa foi criado a partir de cinco perguntas abertas, as quais "permitem ao informante responder livremente, usando linguagem própria, e emitir opiniões, possibilitando investigações mais profundas e precisas" (LAKATOS; MARCONI, 2003 p. 204). O questionário contemplou os seguintes questionamentos: a) O objetivo geral da disciplina de Finanças Pessoais é: Possibilitar aos estudantes universitários o desenvolvimento de conhecimentos pertinentes à educação financeira e finanças pessoais, e sua difusão na comunidade. As atividades realizadas junto às escolas de Ensino Médio contribuíram para o alcance desse objetivo? Justifique sua resposta. b) Na sua concepção, esta disciplina, ao longo deste semestre, proporcionou a construção coletiva de conhecimentos relacionados às finanças pessoais? Comente exemplos. c) Produza uma breve reflexão sobre a ação de disseminar a educação financeira junto aos alunos de Ensino Médio (pontos fortes e fracos, sugestões). d) Auto avaliação: escreva sobre a sua postura, como estudante, nesta disciplina e e) Comente sobre a participação do professor (ou professores) que participou (participaram) das atividades nas escolas.

A análise dos dados seguiu pressupostos da técnica da análise do conteúdo, que visou o aprofundamento das conexões, ideias, palavras, frases e resumos coincidentes e divergentes de ideias apresentadas na exposição do conteúdo em sala. Para o autor, a análise de conteúdo consiste em um conjunto de técnicas que objetivam descrever o teor das mensagens e proporcionar reflexão ao pesquisador, tanto no aprofundamento da análise, quanto no alcance dos resultados mais concretos da pesquisa (BARDIN, 2004).

A categorização é um procedimento de agrupamento de sentidos, considerando a parte comum existente entre eles, cujos dados coletados foram previamente analisados. A análise consiste no desmembramento do texto em categoriais agrupadas analogicamente (BARDIN, 2011). A opção por esse método está respaldada no fato de ser a melhor alternativa para estudar valores, opiniões, atitudes e crenças através de dados qualitativos. Portanto, a interpretação dos dados buscou os significados atrelados aos comportamentos e as percepções dos alunos 
universitários durante a aplicação das atividades desenvolvidas nas escolas do Ensino Médio do Vale do Taquari.

\subsection{Elaboração das categorias de análise}

A formação das categorias se concretizou após a seleção do material e da leitura flutuante, cuja exploração foi realizada através da codificação (BARDIN, 2011). A codificação se deu em função da repetição das palavras, que uma vez triangulada com os resultados observados, foram constituindo-se em unidades de registro para então efetuar a categorização progressiva. Adverte-se que as categorias descritas a seguir (Quadro 1) dizem respeito à temática do estudo, não servindo como modelo para qualquer estudo, tendo em vista as idiossincrasias inerentes a cada tema.

Quadro 1 - Categoria Inicial e Intermediária

\begin{tabular}{|c|c|c|}
\hline Categorias Iniciais & Categorias Intermediárias & $\begin{array}{l}\text { Quadros (Questões } \\
\text { Correspondentes) }\end{array}$ \\
\hline \multirow{5}{*}{$\begin{array}{l}\text { A aquisição e difusão do } \\
\text { conhecimento apreendido }\end{array}$} & Aprofundamento das leituras & \multirow{5}{*}{1 e 3} \\
\hline & Estratégias de ensino & \\
\hline & Construção do Conhecimento & \\
\hline & Mudança de perfil & \\
\hline & Crescimento pessoal e profissional & \\
\hline \multirow{5}{*}{$\begin{array}{c}\text { A disciplina sobre } \\
\text { Educação Financeira }\end{array}$} & Saber gastar e economizar & \multirow{5}{*}{2} \\
\hline & Iniciação tardia & \\
\hline & Equilíbrio Financeiro & \\
\hline & Organização pessoal & \\
\hline & Planejamento Financeiro & \\
\hline \multirow{5}{*}{$\begin{array}{l}\text { A integração entre professor e } \\
\text { aluno no processo de ensino e } \\
\text { da aprendizagem }\end{array}$} & Troca de experiência & \multirow{5}{*}{4 e 5} \\
\hline & Comprometimento & \\
\hline & Dedicação & \\
\hline & Teoria e Prática & \\
\hline & Confiança & \\
\hline
\end{tabular}

Fonte: Elaborado pelos autores.

\section{RESULTADO E ANÁLISES DOS DADOS}

Nesta seção, serão apresentados os dados coletados com a seleção das respostas mais relevantes. Em seguida, passa-se a análise dos depoimentos com base nas categorias levantadas, conforme Quadro 1, anteriormente apresentado.

\subsection{A aquisição e difusão do conhecimento apreendido.}


A aglutinação das questões 1 e 3, que resultou nessa categoria, deu-se pela proximidade conceitual no tocante à construção do conhecimento apreendido pelos graduandos no desenvolvimento do projeto "Educação Financeira”, nas escolas do Vale do Taquari.

Entretanto, para alguns autores, há diferença entre a aprendizagem e o ensino, sendo que o primeiro está diretamente focado no aluno e o segundo, no professor. Esses elementos se completam dentro de um mesmo processo: a formação. Para se compreender a distinção entre eles, o termo ensinar é associado a instruir, comunicar conhecimentos ou habilidades, fazer saber, mostrar, guiar e dirigir, sendo ações pertinentes ao professor. Já o termo aprender, segundo o Masetto (2003), significa buscar informações, rever a própria experiência, adquirir habilidades, adaptar-se às mudanças, descobrir significado nos seres, nos fatos, nos fenômenos e nos acontecimentos (MASETTO, 2003, p. 35 e 36). Dessa forma, percebe-se que somente com a parceria entre esses dois personagens é que se dá a aprendizagem, tendo como pano de fundo o que cada um pode contribuir para que isso aconteça. Nessa perspectiva, a aprendizagem é um processo singular, apropriado do conhecimento a partir das experiências vivenciadas (GONZÁLEZ, 2008). É o que se percebe na resposta do aluno A25:

As atividades realizadas [...] contribuíram sim para o alcance do objetivo [...], pois possibilitou o meu desenvolvimento perante conhecimentos sobre a área financeira, também pude fazer essa difusão na comunidade, tendo uma experiência significativa nas escolas repassando o conhecimento para os alunos e obtendo contato com a sociedade escolar adolescente (ALUNO 25, 2018).

Compreende-se assim, que o aprender se torna mais desafiador quando o aluno se sente membro do processo e partícipe das atividades e métodos desenvolvidos para a aprendizagem. O aprender é um ato de conhecimento da realidade concreta, ou seja, o prazer pelo aprender não é natural em todos, mas, cabe o despertar da curiosidade e a necessidade de cultivar novos conhecimentos (LIBÂNEO, 1990).

Resumidamente, os alunos A1 e A25 apontaram:

[...] tivemos que dominar e aprofundar nossos conhecimentos da disciplina para poder transmitir aos alunos o maior e melhor conteúdo possível, tirando dúvidas e repassando exemplos a eles. (ALUNO 1, 2018)

[...] disseminar a educação financeira aos alunos de escolas de Ensino Médio abordando o tema finanças pessoais é de grande importância, o ideal seria mesmo poder passar esse conhecimento para todos os alunos o máximo possível. (ALUNO $25,2018)$

A maioria dos alunos da graduação perceberam que ensinar exige muito mais dedicação do que o tempo previsto em sala de aula e que a forma de apresentar o conhecimento sobre Educação Financeira deve ser previamente analisada, contemplando o nível de entendimento 
de todos envolvidos no aprendizado. Portanto, o conhecimento que o aluno transfere representa uma resposta à compreensão crítica por ele adquirido.

\subsection{A disciplina sobre Educação Financeira.}

A questão 2, resultante dessa categoria, foi compreendida a partir da importância do planejamento financeiro alcançado pelos graduandos mediante a organização pessoal com relação a saber gastar e economizar. Compreender e praticar a Educação Financeira pode ser uma das formas de se ter uma vida mais equilibrada financeiramente. Quanto mais cedo, melhor se aprende a lidar com o dinheiro.

A Educação Financeira, "é um processo que contribui, de modo consistente, para a formação de indivíduos e sociedades responsáveis, comprometidos com o futuro" (BACEN 2013, p.1). Para que se torne possível esse processo, é indispensável pensar a respeito do conhecimento de determinadas práticas sem ter em mente um espaço para que sejam desenvolvidas. Pensando nisso, a escola "é o local estratégico para proporcionar o conhecimento contribuindo na formação da vida pessoal com a inserção dos assuntos relacionados à Educação Financeira" (PETER E PALMEIRA 2013, p. 1). A inclusão da Educação Financeira na grade curricular a partir dos cursos do nível fundamental já se tornava uma realidade na contribuição para a capacidade do aluno em controlar suas finanças, não somente para as questões pessoais, como, também coletivamente (MONTEIRO, 2012).

Evidenciou-se que é indispensável que a disciplina seja disponibilizada o quanto antes na formação básica do aluno para que atinja a idade adulta com responsabilidade sabendo planejar seus gastos (PEREIRA et al, 2009). Com informações, entendimentos e orientações claras, os alunos adquirem os valores e as competências necessárias para se tornarem conscientes das oportunidades e dos riscos a elas associados, como relatam os alunos A5 e A18:

[...] através das pesquisas em grupo sobre o assunto finanças conseguimos criar uma visão para o nosso futuro, pensando em como podemos obter uma vida mais tranquila daqui a algum tempo [...] ensinando e mostrando exemplos do que é preciso fazer para ter uma vida financeira sem ter preocupações. (ALUNO 5, 2018)

[...] nossos conhecimentos com certeza melhoraram em relação a este assunto. Desde a poupança até investimentos com certeza houve um aumento significativo. (ALUNO $18,2018)$

É possível perceber, nas respostas acima que a disciplina de Educação Financeira contribui na construção individual e coletiva de conhecimentos relacionados às finanças pessoais. Apostando nesse crescimento, a OABPREV esclarece que 96 mil crianças e jovens de todo o Brasil terminaram o ano de 2017 educadas financeiramente pelo Programa Educação 
Financeira nas Escolas-DSOP, cuja previsão é aumentar esse número em $20 \%$ em 2018 (OABPREV 2017). No propósito de auxiliar a criança, o pré-adolescente, o adolescente, os jovens e os adultos na administração de seus rendimentos, a importância da Educação Financeira é percebida pela contribuição do aluno A19:

[...] buscamos da melhor forma possível enriquecer nosso conhecimento para passar adiante nosso estudo e com isso ver a dificuldade dos jovens quanto a esse assunto e em cima de seus questionamentos buscamos para o segundo momento, além do material que tínhamos, tirar dúvidas quanto a situações por eles vividas. (ALUNO 19, 2018)

Assim, com "a junção de teoria com a prática sobre a Educação Financeira" desde o início da vida escolar, é possível que os alunos construam hábitos que reforcem ainda mais o aprendizado ao longo da vida até chegar na fase adulta, conforme contribuição do aluno A14.

\subsection{Integração entre professor/aluno no processo de ensino e de aprendizagem}

Essa categoria originou-se das questões 4 e 5, enfatizando a troca de experiência entre professor e aluno, baseado na confiança e no comprometimento de ambos. A relação professoraluno é uma condição indispensável dentro dos processos de ensino e de aprendizagem, pois, essa cumplicidade produz sentido ao processo educativo. Dessa interação professor-aluno, pode-se observar dois aspectos: o repasse do conhecimento e a relação pessoal entre ambos, seguindo as normas escolares que disciplinam todo o contexto.

A força dessa relação professor e aluno é expressiva e alcança variados resultados. De acordo com Aquino (1996), "a relação entre professor-aluno é muito importante, a ponto de estabelecer posicionamentos pessoais em relação à metodologia, à avaliação e aos conteúdos" (AQUINO, 1996 p.34). O aluno A22 deixa claro que:

[...] foi de extrema importância, tendo em vista a inexperiência do grupo, logo o professor iniciou a apresentação informando sobre o projeto que nos deixou mais seguros em nossa apresentação. Ao longo do desenvolvimento das atividades o professor foi dando suporte e auxiliando a sanar dúvidas que os alunos do ensino médio apresentavam (ALUNO 22, 2018).

Segundo Freire (1996), "toda prática educativa demanda a existência de sujeitos, um, que ensinando, aprende, outro, que aprendendo ensina". A base do sucesso dessa relação está centrada na dedicação, na confiança, no respeito, em que o professor consegue orientar o aluno para seu desenvolvimento, tornando-o mais apto para as decisões que precisam ser tomadas (FREIRE 1996, p.77). Essa perspectiva é reforçada pela resposta do aluno A6, quando declara: 
“O professor ajudou com exemplos práticos em alguns momentos, e que [...] os alunos interagissem melhor com o tema" (ALUNO 6, 2018).

No processo de ensino e de aprendizagem, a interação professor-aluno é constituída de uma via de mão-dupla, ou seja, pela influência do professor sobre o aluno, como também, do aluno sobre o professor, existindo uma relação com efeitos recíprocos (BARIANI \& PAVANI, 2008). É possível perceber o resultado dessa interação, em que cada um dos lados contribui com seu melhor, sendo relatado pelos alunos A11 e A18:

Muito importante a presença do professor. Passou experiência e calma para nós palestrantes, e agregou muito valor para os alunos do ensino médio que tiveram a oportunidade de tirar dúvidas. (ALUNO 11, 2018)

Acredito que tive comprometimento em relação a atividade, [...] e quis passar isso a eles da forma mais fácil possível. (ALUNO 18, 2018)

Assim, a desvinculação entre o ensino e a aprendizagem não deve ocorrer, uma vez que essa relação abrange todas as dimensões do processo de construção do conhecimento, o qual é desenvolvido dentro e fora da sala de aula. Logo, é importante transpor os papeis formais da atividade docente, dando estrutura ao aprendizado, orientando e ajudando os alunos a estudar e aprender.

\section{CONSIDERAÇÕES FINAIS}

As abordagens teóricas que fundamentam esse artigo demonstram a importância do tema sobre a Educação Financeira, tanto para os alunos nas escolas quanto para o contexto social, desde o início de sua vida escolar. Em sala de aula, os alunos iniciam o processo de formação de hábitos e, em razão do contato com o tema, passam a desenvolver tais conhecimentos em seus comportamentos cotidianos.

Conforme os resultados alcançados na primeira categoria, foi percebido que a aprendizagem é um processo individual que se apropria do conhecimento, a partir das experiências vivenciadas. Os graduandos afirmaram que a atividade proporcionou não só a difusão desses conhecimentos no meio social, como também o aprimoramento da compreensão crítica. Com relação à segunda categoria, os resultados apontaram a importância do conteúdo da disciplina na construção da cidadania do aluno, tendo em vista sua implementação nas bases curriculares desde o Ensino Fundamental.

Por fim, na terceira categoria observou-se a importância da sincronia entre ensino e aprendizagem na relação professor e aluno, exigindo dedicação, confiança e respeito de ambos na ação de orientar para o desenvolvimento pessoal e profissional. Conclui-se, portanto, que a 
Educação Financeira como tema transversal, oferece vantagens para os alunos, mostrando-lhes a importância de uma vida financeira equilibrada, uma vez que o ato de planejar gastos reflete na capacidade de conquistar um futuro melhor.

\title{
THE IMPORTANCE OF FINANCIAL EDUCATION IN THE UNIVERSITY: AN APPROACH TO THE PROFESSIONAL AND PERSONAL TRAINING OF UNIVERSITY UNIVERSITY STUDENTS
}

\begin{abstract}
:
This article aims to analyze the importance of Financial Education for university students of a Higher Education Institution located in Rio Grande do Sul. The theoretical basis is based on: Savoia (2007); Pereira (2009); Ewald (2011); Monteiro (2012); Bacen (2013); Hofman and Moro (2013) and Modernell (2014). In this study, which has a qualitative approach, the collected data were acquired through the application of a questionnaire containing five questions. The students involved are graduates of a Higher Education Institution located in Rio Grande do Sul. These students are linked to the Organizational Management Center (CGO) through the Personal Finance discipline. The data collected allowed us to construct three categories of initial analysis: a) the acquisition and diffusion of knowledge learned; b) discipline on Financial Education; and c) the integration between teacher and student in the teaching and learning process. To analyze the data, we used the technique of content analysis. The results point out the importance of Financial Education in personal and professional formation of the person. They also pointed out that it should be made available as soon as possible in basic education in schools so that the human being, in adulthood, can plan his expenses with responsibility and balance.
\end{abstract}

Keywords: Community. College students. Financial education. High school. Personal finances.

\section{REFERÊNCIAS}

AQUINO, J. G. A relação professor-aluno: do pedagógico ao institucional. São Paulo: Summus, 1996.

ALVES, A. J. O planejamento de pesquisas qualitativas em educação. Cadernos de Pesquisa. (77): 53-61. São Paulo: 1991.

BANCO CENTRAL DO BRASIL. 2013. O Programa de Educação Financeira do Banco Central. Disponível em: < http://www.bcb.gov.br/pre/bcuniversidade/introducaoPEF.asp>. Acesso em: 15 mar. 2018.

BARDIN, L. Análise de conteúdo. Lisboa: Edições 70, 2004.

Análise de conteúdo. SP: Edições 70, 2011.

BARIANI, I. C.; PAVANI, R. Sala de aula na universidade: espaço de relação interpessoais e participação acadêmica. Revista Estudos de Psicologia / 25(1) / 67-75/ Jan- mar / 2008.

ENEF: Estratégia Nacional de Educação Financeira. São Paulo, 2011. Disponível em: <http://www.vidaedinheiro.gov.br/index.php>. Acesso em 16 mar. 2018.

EWALD, L. C. Alfabetização Financeira, Pinhais, v. 3, n. 47, p. 4-5, abr. 2011. Entrevista concedida a Revista Impressão Pedagógica. Acesso em: 10 abr. 2018. 
FAVERI, D. B. de; KROETZ, M.; VALENTIM, I. Educação financeira para crianças. 2013. Disponível em: <http://webcache.googleusercontent.com/search?q=cache:DQkI_Grt4cJ:www.aedb.br/seget/artigos12/64316569.pdf $+\& \mathrm{~cd}=5 \& \mathrm{hl}=\mathrm{pt}-\mathrm{BR} \& \mathrm{ct}=\mathrm{clnk} \& \mathrm{gl}=\mathrm{br}>$. Acesso em: 12 abr. 2018.

FRANZONI, F.; MARTINS, S. N.; QUARTIERI, M. T. A Educação Financeira Como Política Pública no Ensino Básico: Algumas Reflexões. Rev. Educ., Cult. Soc., Sinop/MT/Brasil, v. 8, n. 2, p. 383-395, jul./dez. 2018. https://sinop.unemat.br/projetos/ revista/index.php/educacao/article/view/3226/0. Acesso em julho 2018.

FREIRE, P. Pedagogia da autonomia: saberes necessários à prática educativa. 20 ed. São Paulo: Paz e Terra, 1996.

GIL, A. C. Como elaborar projetos de pesquisa. 4. ed. São Paulo: Atlas, 2002.

GONZÁLEZ, R. O Sujeito que Aprende: desafios do desenvolvimento do tema da aprendizagem na psicologia e na prática pedagógica. In: TACCA, Maria Carmem V. R. Aprendizagem e Trabalho Pedagógico. Campinas, SP: Alínea. 2008

HOFMANN, R. M.; MORO, M. L. F. Educação matemática e educação financeira: perspectivas para a ENEF. Zetetiké: Revista de Educação Matemática, v. 20, n. 38, p. 3754, 2013. Disponível em: <http://www.fae.unicamp.br/revista/index.php/zetetike/article/view/ 2814 >. Acesso em 23 mar. 2018.

KIOYOSAKI, Robert T.; LECHTER, S. L. Pai Rico, pai pobre: O que os ricos ensinam a seus filhos sobre dinheiro. Ed. 66 ${ }^{\circ}$, Rio de Janeiro: Elsevier, 2000.

LAKATOS, E. M. \& MARCONI, M. de A. Fundamentos de metodologia científica 1. 5. ed. - São Paulo: Atlas 2003.

LIBÂNEO, José Carlos. Democratização da Escola Pública. São Paulo: Loyola, 1990.

MARTINS, J. P. Educação financeira ao alcance de todos. São Paulo: Fundamento Educacional, 2004.

MASETTO, M. Competência pedagógica do professor universitário. São Paulo, 2003.

MODERNELL, Á. (2014). Educação financeira no Ensino Fundamental I: desafios e possibilidades. Disponível em: http://www.edicoessm.com.br/sm_resources_center/ somos_mestres/formacaoreflexao/educacao-financeira.pdf. Acesso em 24 mar. 2018.

MONTEIRO, C. (2012) A necessidade de um novo olhar para a educação brasileira. Disponível em: <http://comoempreender.com/a-necessidade-de-um-novo-olhar-para-aeducacao-financeira/>. Acesso em: 12 mar. 2018.

OECD (Organização de Cooperação e de Desenvolvimento Econômico). OECD 's Financial Education Project. Assessoria de Comunicação Social, 2012. Disponível em: <www.oecd.org/ >. Acesso em: 17 mar. 2018. 
OABPREV - http://www.oabprev-pr.org.br/noticias-detail.php?id=722\&tit=educacaofinanceira-nas-escolas-aumento-de-20-em-2017. Acesso em: 10/04/2018.

PEREIRA, Débora Hilário; [ et al.]. Educação Financeira infantil: seu impacto no consumo consciente. São Paulo. 2009. Disponível em: <http://www.educacaofinanceira.com.br/ tcc/impactoconsumoconsciente.pdf >. Acesso em: 12 mar. 2018.

PETER, L. D.; PALMEIRA, E. M. Estudo sobre a educação financeira como disciplina escolar a partir das séries iniciais. 2013. Disponível em: $<$ http://atlante.eumed.net/educacaofinanceira/>. Acesso em 23 nov. 2013.

SAVOIA, J. R. F.; SAITO, A. T.; SANTANA, F. de A. Paradigmas da Educação Financeira no Brasil. Revista de Administração Pública, v. 41, número 6 - Rio de Janeiro, 2007. Disponível em: http://www.scielo.br/scielo.php?pid=S003476122007000600006\&script=sci_arttext. Acesso em: 21/03/2018.

TEIXEIRA, A. de O. et al. Vantagens e desvantagens da implantação da disciplina educação financeira nas escolas de ensino médio na cidade de pinhais - $P R$ pinhais/PR 2010. 2010. 82 f. Monografia (Graduação em Administração de Empresas) - Faculdades de Pinhais, Pinhais, 2010. Acesso em 12 de mar. 2018.

TRIVIÑOS, A. N. da S. Introdução à pesquisa em ciências sociais: a pesquisa qualitativa em educação. São Paulo: Atlas, 2008. 